\title{
Simulation Game Outcomes: A Multilevel Examination of Knowledge Sharing Norms, Transactive Memory Systems, and Individual Learning Goal Orientations
}

Janice Francis Super Ph.D.

Murray State University, jsuper@murraystate.edu

Teresa K. Betts Ph.D.

Murray State University, tbetts1@murraystate.edu

Heath Keller Ph.D.

Murray State University, rkeller@murraystate.edu

Joy Humphreys Ph.D.

Murray State University, jhumphreys4@murraystate.edu

Follow this and additional works at: https://digitalcommons.murraystate.edu/faculty

\section{Recommended Citation}

Super, J. F., Betts, T. K., Keller, H., \& Humphreys, J. R. (2020). Simulation Game Outcomes: A Multilevel Examination of Knowledge Sharing Norms, Transactive Memory Systems, and Individual Learning Goal Orientations. Simulation \& Gaming. https://doi.org/10.1177/1046878120943255

This Journal Article is brought to you for free and open access by Murray State's Digital Commons. It has been accepted for inclusion in Faculty \& Staff Research and Creative Activity by an authorized administrator of Murray State's Digital Commons. For more information, please contact msu.digitalcommons@murraystate.edu. 


\section{Simulation \& Gaming}

\section{Simulation Game Outcomes: A Multilevel Examination of Knowledge Sharing Norms, Transactive Memory Systems, and Individual Learning Goal Orientations}

\begin{tabular}{|c|c|}
\hline Journal: & Simulation \& Gaming \\
\hline Manuscript ID & SG-19-022.R3 \\
\hline Manuscript Type: & Research Article \\
\hline Keywords: & $\begin{array}{l}\text { computer simulation < simulation/gaming, educational games }< \\
\text { simulation/gaming, educational }<\text { Field }\end{array}$ \\
\hline Abstract: & $\begin{array}{l}\text { Background: Because computer-based simulation games are widely } \\
\text { used in university classrooms, it is important to investigate factors which } \\
\text { can lead to effective student team performance and positive individual } \\
\text { outcomes. } \\
\text { Aim: This correlational study aimed to examine the effects of knowledge } \\
\text { sharing norms, transactive memory systems, and individual learning goal } \\
\text { orientations on game outcomes. } \\
\text { Method: The setting for this study was an undergraduate logistics and } \\
\text { supply chain class. The class uses a serious simulation game which is } \\
\text { designed to realistically mimic the business transactions within an } \\
\text { enterprise resource planning system (ERP). Cross-sectional surveys } \\
\text { captured individual learning goal orientations. After multiple rounds of } \\
\text { simulation game play, subsequent surveys captured student reactions, } \\
\text { perceptions of knowledge sharing behaviors, and transactive memory } \\
\text { systems. } \\
\text { Results: Two sets of analyses were conducted using a sample of } 100 \\
\text { undergraduates performing in } 42 \text { teams. At the group-level, OLS } \\
\text { regression results suggest that, while there was no effect on objective } \\
\text { team performance, knowledge sharing norms enhanced perceptions of } \\
\text { team performance, and this effect was mediated through the } \\
\text { development of transactive memory systems. For individual-level } \\
\text { outcomes, multilevel results suggest that knowledge sharing norms were } \\
\text { positively related to satisfaction with the team, but not satisfaction with } \\
\text { the task. However, transactive memory systems were positively related } \\
\text { both satisfaction with the team and satisfaction with the task. Individual } \\
\text { learning goal orientation was positively related to satisfaction with the } \\
\text { task but not satisfaction with the team. } \\
\text { Conclusion: Our findings suggest that learning goal orientations and } \\
\text { norms for knowledge sharing are linked to positive outcomes of team- } \\
\text { based simulation game learning activities. Because learning goal } \\
\text { orientations are malleable and norms for knowledge sharing can be } \\
\text { encouraged, these factors are within the influence of the instructor. As } \\
\text { such, they should be nurtured and developed through the active } \\
\text { encouragement of experimentation, exploration, and communication } \\
\text { between team members. }\end{array}$ \\
\hline
\end{tabular}


1

2

3 4 performance and positive individual outcomes.

5

6 7 outcomes. and transactive memory systems.

\section{Abstract}

Background: Because computer-based simulation games are widely used in university classrooms, it is important to investigate factors which can lead to effective student team

Aim: This correlational study aimed to examine the effects of knowledge sharing norms, transactive memory systems, and individual learning goal orientations on game

Method: The setting for this study was an undergraduate logistics and supply chain class.

The class uses a serious simulation game which is designed to realistically mimic the business transactions within an enterprise resource planning system (ERP). Cross-sectional surveys captured individual learning goal orientations. After multiple rounds of simulation game play, subsequent surveys captured student reactions, perceptions of knowledge sharing behaviors,

Results: Two sets of analyses were conducted using a sample of 100 undergraduates performing in 42 teams. At the group-level, OLS regression results suggest that, while there was no effect on objective team performance, knowledge sharing norms enhanced perceptions of team performance, and this effect was mediated through the development of transactive memory systems. For individual-level outcomes, multilevel results suggest that knowledge sharing norms were positively related to satisfaction with the team, but not satisfaction with the task. However, transactive memory systems were positively related both satisfaction with the team and satisfaction with the task. Individual learning goal orientation was positively related to satisfaction with the task but not satisfaction with the team. 
23 Conclusion: Our findings suggest that learning goal orientations and norms for

24 knowledge sharing are linked to positive outcomes of team-based simulation game learning 25 activities. Because learning goal orientations are malleable and norms for knowledge sharing

26 can be encouraged, these factors are within the influence of the instructor. As such, they should

27 be nurtured and developed through the active encouragement of experimentation, exploration, 28 and communication between team members.

29

30 Keywords: computer-based simulation games, knowledge sharing, team cognitions, transactive 31 memory systems, affective reactions. 
Simulation Game Outcomes: A Multilevel Examination of Knowledge Sharing Norms, Transactive Memory Systems, and Individual Learning Goal Orientations

Computer simulation games have long been a staple in high-stakes training environments, such as military teams, surgical units, and emergency first responders (Hays, 2005). These sophisticated simulation tools provide a realistic, yet safe, learning environment; one in which mistakes can be made without incurring expensive equipment loss or endangering human life (Bell, Kanar, \& Kozlowski, 2008). As the popularity of video gaming has exploded, business educators have also seen the merit of incorporating instructional content into an interactive simulation framework, thereby capitalizing on the entertainment value inherent in games. Indeed, as technology has evolved and cost barriers have lowered, simulation-based training (SBT) tools have become ubiquitous in workplace training and university settings (Bell \&

Kozlowski, 2008; Faria, Hutchinson, Wellington, \& Gold, 2009; Faria \& Wellington, 2004).

Often delivered in the form of computer-based simulation games, the power of SBT lies in its ability to mimic reality. In the field of workforce training, this aspect of SBT is invaluable, as it enables individuals to become proficient at their job without risk to themselves or others. Consequently, one particularly promising approach to SBT training has been to view the individual as an active participant in the learning process. In this context, the focus is on achievement motivation and self-regulatory learning behaviors as people explore and experiment with the simulation game, learning through trial and error (Bell \& Kozlowski, 2009).

In addition to individual learning, computer-based simulations are also conducive to developing the cognitive structures and relational interfaces necessary for effective team functioning (Kozlowski \& DeShon, 2004). We live in an era of technology, and most jobs are 
55 positioned within the realm of a knowledge economy. As such, work has become increasingly complex. This complexity requires people to work together, interact with each other, share

57 information, and commit their combined talents and energies to the accomplishment of a single 58 goal (Kozlowski \& Bell, 2013). Learning resides within an individual. However, people who 59 work closely and intensively with each other will often develop special group-level cognitions 60 whereby they share understandings and mental representations of the team's task environment 61 (Klimoski \& Mohammed, 1994; Lewis, Lange, \& Gillis, 2005). Group level cognitions reduce 62 the mental load on any one member of the team. This is particularly beneficial in situations with 63 intense informational demands. Consequently, when team coordination is highly developed, 64 team cognitions can ultimately improve team performance (DeChurch \& Mesmer-Magnus, 65 2010). In terms of development, these team-level cognitive properties "emerge" as individuals 66 within the group interact with each other over time. This is a complex evolution that requires 67 multilevel theoretical conceptualizations (Kozlowski \& Klein, 2000; Kozlowski \& Bell, 2008). computer-based simulation games in the training of dynamic decision-making teams (Kozlowski

72 \& DeShon, 2004; Salas, Rosen, Held, \& Weissmuller, 2009), less emphasis has been paid on 73 effective ways to incorporate these learning tools into the university setting (Salas, Wildman, \& 74 Piccolo, 2009). The university classroom is unique in that students must complete a core 75 curriculum, (e.g., management, accounting, finance, and logistics). While this battery of 76 coursework is beneficial for an individual's overall understanding of the business environment, it 77 may contain certain classes that can be challenging or even intimidating for some students. In 
78 these situations, simulation games, with their ability to provide a realistic, yet harmless, learning

79 environment, can be a powerful learning aide to help students master difficult material and

80 develop critical thinking skills (Lovelace, Eggers, \& Dyck, 2016; Salas, Wildman, \& Piccolo,

81 2009). However, in addition to delivering task-relevant material, the simulation gaming

82 environment can also be leveraged to develop some of the softer skills needed for teamwork and

83 collaborative problem-solving (Marlow, Salas, Landon, \& Presnell, 2016). An educational tool

84 that could help simultaneously develop task and team competencies within the undergraduate

85 curriculum would fulfill a pressing need. To illustrate, a recent report from the National

86 Association of Colleges and Employers (NACE: 2016) indicated that, while employers consider

87 critical thinking, problem-solving, teamwork, and collaboration to be essential, there continues to

88 be a significant deficit in recent new hire proficiencies and readiness. Indeed, this has been a

89 consistent and troubling trend over the last few years as educators, employers, and researchers

90 have noted the need to incorporate interpersonal, collaborative, and team-based skills into the

91 business curriculum (Bedwell, Fiore, \& Salas, 2014; Chen, Donahue, \& Klimoski, 2004; Ritter,

92 Small, Mortimer, \& Doll, 2018). As a teaching and learning tool, simulation games can provide

93 the relevant instructional content which promotes learning while also fostering collaborative,

94 team-based behaviors. However, while simulation games hold much promise, there remains a

95 lack of research on the specific motivational mechanisms, group interactions, and causal

96 pathways through which these dual outcomes can be fostered (Marlow et al., 2016).

97 In this study, we examine the impact of individual achievement motivation and team

98 knowledge sharing behaviors on satisfaction variables and team performance outcomes in the

99 context of a complex and serious simulation game. Our goal is to advance an understanding of

100 determinants of student success in computer-based simulation games, at the individual and team 
101 levels. We recognize that the repetitive rounds of play inherent in computer-based simulation

102 games allow for team formation and team processing. This corresponds to the general

103 framework of the IMOI (input-mediator-output-input) model of teamwork (Ilgen, Hollenbeck, 104 Johnson, \& Jundt, 2005). Within IMOI frame, we look at individual learning goal orientation 105 and group-level knowledge sharing norms as our input variables. To understand our group-level, 106 mediating variable, we base our thinking in the foundations of social exchange theory (SET) and 107 the premise of reciprocity (Cropanzano \& Mitchell, 2005). SET predicts that high-quality 108 knowledge exchange and interpersonal communications will result in the formation of team 109 cognitive structures such as team mental models or transactive memory systems and that these 110 team-level cognitions result in positive team and individual outcomes (Fiore, Salas, \& Cannon111 Bowers, 2001; Bachrach et al., 2019). Therefore, congruent with the concepts of social 112 exchange, we expect that reciprocal knowledge sharing interactions will result in the formation 113 of transactive memory systems. Furthermore, we expect that these transactive memory systems 114 will enhance team performance and positively influence individual reactions to the game.

\section{Theoretical Background}

As technology has become more advanced, business simulation games have emerged as a

117 popular learning tool. A survey from the late 1990s found that over $97 \%$ of business schools 118 used simulation games (Faria, 1998), while a later survey found that a substantial number of 119 faculty in AACSB institutions had used a business simulation game in the classroom at least 120 once (Faria \& Wellington, 2004). The current generation of business simulation games provides 121 an interactive and experiential learning environment where students and trainees can be 122 immersed in a realistic situation and learn from the consequences of their decisions. Cognitive 123 structure refers to memory and knowledge bases, while affective structures involve motivations 
124 and attitudes. Simulation games can be effective training tools because, through an interaction of

125 external and internal mechanisms, they target both cognitive and affective structures (Sitzmann,

126 2011; Tennyson \& Jorczak, 2008). Although research has typically focused on individual

127 learner outcomes, an understudied aspect of simulation games is their potential to encourage

128 teamwork and cooperative behaviors such as knowledge sharing (Marlow et al., 2016).

129 Knowledge Sharing in Teams

130 Work has become complicated and dependent on technology, thereby making it difficult

131 for an individual to function alone. As such, companies depend on teams to solve problems and

132 deal with sudden and unexpected contingencies and events (Kozlowski \& Bell, 2013). Because

133 of this increasing complexity, teams are being thought of, not merely as vehicles to perform

134 tasks, but as information processing units (Hinsz, Tindale, \& Vollrath, 1997). Effective teams

135 develop through the emergence and coalescence of individual knowledge, goals, efficacy, and

136 skill (DeShon, Kozlowski, Schmidt, Milner, \& Wiechmann, 2004; Kozlowski \& Bell, 2013).

137 When teams effectively share and combine information and knowledge, they are able to achieve 138 superior outcomes (Mesmer-Magnus \& DeChurch, 2009).

139 Outcomes of team knowledge sharing behaviors. Knowledge and time are valuable

140 commodities, and, unless there is a compelling reason, people are often reluctant to take the time 141 and make an effort to share what they know. Yet we know that, over time, people who work 142 together in teams often develop highly cohesive bonds, and that these relationships, which are 143 built on trust and mutual liking, can result in team synergies which are beneficial to the 144 organization (Mathieu, Hollenbeck, van Knippenberg, \& Ilgen, 2017). One explanation for the 145 development of team cohesion lies in the reciprocity rules that are at the heart of positive social 146 exchange (Cropanzano \& Mitchell, 2005). Reciprocity is conceptualized as a series of 
147 interdependent exchanges whereby an action on the part of one person leads to a response by the 148 other. If these exchanges are positive in nature, quality relationships develop over time, which 149 can facilitate knowledge sharing and ultimately enhance performance (Bartol, Liu, Zeng, \& Wu, 150 2009; Quigley, Tesluk, Locke, \& Bartol, 2007). The nature of reciprocal response can be 151 thought of as both behavioral and relational (Cropanzano et al., 2017). Positive individual 152 outcomes such as organizational citizenship behaviors and trust have been examined in 153 conjunction with relational, reciprocal exchange (Eisenberger, Armeli, Rexwinkel, Lynch, \& 154 Rhoades, 2001; Dirks \& Ferrin, 2001; Molm, Takahashi, \& Peterson, 2000). Since knowledge 155 sharing is an activity based on reciprocity and an integral part of team functioning, we would 156 expect knowledge sharing norms and reciprocal exchanges to encourage an overall positive 157 climate and an environment for cooperation. As a result, team members should have a better 158 social experience, and this enhanced social experience should make members happier and more 159 satisfied with their respective teammates. However, the establishment of knowledge sharing norms should have positive effects 161 beyond affective reactions to others on the team. Knowledge is often shared in the form of 162 information, and there is a rich body of research that looks at the patterns, effects, and outcomes 163 of information sharing in groups (De Dreu, Nijstad, \& van Knippenberg, 2008; Stasser \& Titus, 164 1985, 1987). The original assumption was that the quality of decision-making was a 165 mathematical function of the way in which information was distributed amongst group members 166 (Stasser \& Titus, 1985, 1987; Wittenbaum, Hollingshead, \& Botero, 2004). Later, researchers 167 began to acknowledge that the quality of information exchange was also a function of member 168 motivations: in particular, epistemic and social motivations (Nijstad \& De Dreu, 2012). In these 169 models of group information sharing, the group members' motivation to learn and acquire a deep 
170 understanding of the task at hand, along with their willingness to cooperate with others, has a

171 significant impact on the quality of information exchange and group decision-making (De Dreu,

172 Nijstad, \& van Knippenberg, 2008). So, in team settings, research findings suggest that such

173 factors as the prosocial proclivities, perceived expertise, and social status of group members; the

174 quality of leadership exchanges; and the type of team communications have a significant effect

175 on performance outcomes (De Dreu, Nijstad, \& van Knippenberg, 2008; Marlow, Lacerenza,

176 Paoletti, Burke, \& Salas, 2018; Mohammed \& Dumville, 2001). In terms of performance

177 outcomes, the effects of information and knowledge sharing have been shown to affect both the

178 task and socio-emotional functioning of the team (Mesmer-Magnus \& DeChurch, 2009;

179 Wittenbaum, Hollingshead, \& Botero, 2004). In other words, members who share knowledge

180 are not only happier with each other; the information exchange also boosts task satisfaction and

181 actual task performance. Therefore, in this study, we would expect knowledge sharing norms to

182 affect team and task satisfaction, as well as the overall performance outcomes of the team.

Hypothesis 1a: Knowledge sharing norms will be positively related to a) satisfaction with the team and b) satisfaction with the task.

Hypothesis 1b: Knowledge sharing norms will be positively related to a) perceived team performance and b) actual team performance.

\section{Knowledge sharing norms and the development of transactive memory systems.}

188 When people are working closely together on a task, they will often develop special cognitive 189 structures to achieve their common goals. In general, these cognitive structures are labeled team 190 cognitions, and they are usually conceptualized in two different ways: team mental models and 191 transactive memory systems (Ilgen et al., 2005; Fiore, Salas, \& Cannon-Bowers, 2001). Team 192 mental models (TMM) refer to shared cognitions, where knowledge is communal and redundant. 
193 TMM is particularly useful in dynamic situations where coordination and backup behaviors are essential (e.g., emergency response teams and military units) (Cannon-Bowers, Salas, \& Converse, 1993; Klimoski \& Mohammed, 1994). The second type of team cognition, transactive memory systems (TMS), describes the development and utilization of individual team member expertise. Initially conceived as a type of specialized team cognitive strategy, TMS

198 explains how group members can, together, achieve a complex task that would be difficult, if not 199 impossible, for one person, working alone (Ren \& Argote, 2011).

In essence, TMS involves two components: a group level memory structure, (who knows 201 what) and transactive processes to utilize that structure (Ren \& Argote, 2011). Since the concept 202 was first proposed, TMSs have been observed and studied in a wide variety of laboratory and 203 field settings (Hollingshead, 1998; Lewis, 2004). In terms of antecedents, studies have examined 204 the attributes of team members and have found such personal characteristics as critical team 205 member assertiveness to be instrumental in the formation of TMS (Pearsall \& Ellis, 2006). 206 Through laboratory studies, we know that TMSs will naturally occur when people are trained 207 together on a specific task (Lewis et al., 2005; Liang, Moreland, \& Argote, 1995). Cooperative 208 group behaviors, such as communication have also been connected to the development of 209 transactive memory systems. For example, Kanawattahanchai and Yoo (2007) found that task210 oriented communication led, not only to expertise location, but also to cognition-based trust in 211 virtual teams. He, Butler, and King (2007) found that communication in the form of calls or 212 face-to-face meetings led to the formation of specialized team cognitions, but email exchanges 213 did not.

By definition, a team that has established a group norm for knowledge sharing is 215 engaging in cooperative behaviors. These positive and reciprocal behaviors should result in 
Page 11 of 50

216 high-quality relationships, marked by a sense of mutual respect and liking (Blau, 1964; Molm et

217 al., 2000). Moreover, in training situations, when everyone is a novice and in the initial stages of

218 learning, where roles are differentiated, and informational requirements are complex, the

219 establishment of knowledge sharing norms should result in two outcomes: first, individual team

220 members will volunteer to acquire specialized knowledge, and, second, team members trust each

221 other enough to allow that specialization to occur (Marlow et al., 2016). In other words, the

222 team should develop a transactive memory system.

223 Outcomes of transactive memory systems. Transactive memory systems represent a

224 division of cognitive labor, thereby reducing the mental load on individual team members (Lewis

$225 \&$ Herndon, 2011). Teams with a well-developed TMS are able to locate and take advantage of

226 individual talent and expertise. Hence, teams who develop these specialized structures generally

227 perform better on complex, interdependent tasks (Bachrach et al., 2019). In laboratory studies,

228 teams who take advantage of group member expertise perform better on experimental tasks (He,

229 Butler, King, 2007; Lewis, Lange, \& Gillis, 2005; Pearsall \& Ellis, 2006). Generalizing to a

230 broader base, studies looking at the effects of TMS have been conducted in a variety of settings

231 from knowledge workers in consulting and product development teams (Akgün, Byrne, Keskin,

232 Lynn, \& Imamoglu, 2005; Lewis, 2004) to national security teams and EMTs (Jarvenpaa \&

233 Majchrzak, 2008), with an overall consensus that groups who can develop and maintain effective

234 TMSs achieve superior performance outcomes (DeChurch \& Mesmer-Magnus, 2010; Lewis et

235 al., 2005). This positive effect extends to a variety of performance outcomes, including

236 perceived team performance (Bachrach et al., 2019; Zhang, Hempel, Han, \& Tjosvold, 2007).

237 Therefore, since we expect the high-quality relationships that develop from knowledge sharing to

238 result in the formation of transactive memory systems, it would follow that these TMSs would 
239 result in improved team performance outcomes. Consequently, we expect transactive memory 240 systems will mediate the relationship between knowledge sharing norms and team performance 241 outcomes.

Hypothesis 2: Transactive memory systems will mediate the relationship between (a) knowledge sharing norms and actual team performance and between (b) knowledge sharing norms and perceived team performance.

Moreover, being in an environment where information is efficiently and effectively

246 flowing between team members should have benefits beyond those of team performance. People 247 who are part of such a reciprocal exchange should feel a sense of inclusion; they should derive a 248 certain sense of self-worth as they find themselves actively contributing to the success of their 249 team. Indeed, this is consistent with prior research findings, where we see that informational 250 diversity is positively related to satisfaction levels when group differences and conflicts are 251 minimized (Jehn, Northcraft, \& Neale, 1999), when information flows are efficient (Janz, 252 Colquitt, \& Noe, 1997), and when goals are reached as complex, interdependent tasks are 253 competently planned and executed (Saavedra, Earley, \& Van Dyne, 1993).

Research findings continue to support the notion that participating in a specialized 255 knowledge network lends itself to a certain sense of satisfaction. For example, in a recent 256 metanalysis, Bachrach and colleagues (2019) found that well-developed transactive memory 257 systems have beneficial effects on the affective aspects of team performance. In particular, 258 teams with a developed TMS tend to have a more positive assessment of the team's future 259 viability (Lewis, 2004). Transactive memory systems have been shown to bolster the effects of 260 positive intangible team factors. For example, when engaged in knowledge-intensive tasks, trust 261 is positively related to team member satisfaction; this relationship flows through the 
262 development of a transactive memory system (Gockel, Robertson, \& Brauner, 2013). Other

263 studies have shown transactive memory systems to be a mediator between leadership behaviors

264 and team satisfaction, as transactive memory systems mediate the relationship between critical

265 team member characteristics and satisfaction levels (Pearsall Ellis, 2006). In a field study

266 looking at nurse and physician anesthetists who were working under pressure and time

267 constraints, transactive memory had a positive effect on work attitudes, such as job satisfaction

268 and team identification (Michinov, Olivier-Chiron, Rusch, \& Chiron, 2008).

269 These findings make intuitive sense. Since transactive memory systems bolster goal

270 attainment, we would expect team members to experience more satisfaction when they are part

271 of a specialized team and reap the benefits of that specialization. Consequently, because team

272 cognitions originate from reciprocal knowledge exchange, we would expect transactive memory

273 systems to mediate the relationship between knowledge sharing norms and affective team

274 outcomes.

275 Hypothesis 3: Transactive memory systems will mediate the relationship between (a)

$276 \quad$ knowledge sharing norms and satisfaction with the team and between (b)

277 knowledge sharing norms and satisfaction with the task.

278 Achievement Motivation and Learning Goal Orientations

279 One of the most useful concepts in understanding how people perform during the

280 learning process is that of goal orientation. Goal orientation refers to the way in which people

281 view and approach learning and performance in achievement situations. Its earliest conception

282 came from educational psychology, where researchers noted differences in the way children

283 would approach educational achievements (Dweck, 1986). In certain situations, some children

284 would take a deep approach to learning, wanting to internalize and gain personal mastery over 
285 the material; whereas, other children were more interested in obtaining the external approval of 286 others, (e.g., the teacher or parent). Educational psychologists began to refer to these 287 differences as goal orientations. The people who viewed learning as a way to acquire or increase 288 personal competence were considered to have learning goal orientations; whereas, the people 289 who were more concerned with demonstrating competence and meeting performance 290 expectations were considered to have performance goal orientations (Dweck, 1986). examined its effect in multiple areas such as job performance, evaluation, and feedback seeking 296 (VandeWalle, 1997); training effectiveness and trainee reactions (Bell \& Kozlowski, 2002); team 297 cohesiveness and cooperative behaviors (Dierdorff \& Ellington, 2012); and leadership 298 effectiveness (Dragoni, 2005; Porter, Franklin, Swider, \& Yu, 2016). The overwhelming 299 consensus from all this research suggests that learning goals are correlated with positive adaptive 300 behaviors, such as goal establishment, self-monitoring, and persistence in the face of failure 301 (Payne, Youngcourt, \& Beaubien, 2007). Overall, research findings suggest that higher levels of learning goal orientations are 303 linked to a motivation to absorb instructional material and gain proficiencies at a given task. For 304 example, people with higher levels of learning goal orientation are more likely to stay focused on 305 the task at hand and persevere when encountering difficulties (Brown, 2001; Fisher \& Ford, 306 1998). Higher levels of learning goal orientations are linked to an increased use of learning 307 strategies and increased use of self-regulatory mechanisms, such as metacognition (Dierdorff \& 
Page 15 of 50

308 Ellington, 2012; Payne et al., 2007). In a classroom setting, learning goal orientations were

309 linked to higher motivations to learn, which, in turn, were linked to more positive course

310 outcomes, such as grades and satisfaction (Klein, Noe, \& Wang, 2006).

311 Because people with learning or mastery goal orientations are intent on improvement,

312 they are likely to invest in resources that will optimize their outcomes. In today's environment,

313 where work is complex and interdependent, it is reasonable to think that people with mastery

314 goal orientations would see their peers as a valuable source of assistance. In line with the

315 rationale that people view coworkers, colleagues, and peers as assets, scholars have surmised that

316 people with mastery goals are likely to invest in exchange relationships, see the value of

317 reciprocal norms, and seek out avenues to gain and integrate new sources of information

318 (Poortvliet \& Darnon, 2010). Because people with higher learning goal orientations are intently

319 focused on learning the material and gaining mastery of the task, learning goal orientations

320 should be postively related to task satisfaction. Moreover, when working on a complex,

321 interdependent task, people with mastery orientations are likely to recognize the difficulties of

322 operating alone. As a result, they are likely to seek out and form positive alliances with their

323 teammates (Poortvliet \& Darnon, 2010). Therefore, we would expect levels of trait learning goal

324 orientation to have an effect on their reactions to an instructional tool, as well as their

325 perceptions of the people assigned to work with them.

326 Hypothesis 4: Individual learning goal orientations will be positively related to a)

327 satisfaction with the task and b) satisfaction with the team.

328

Insert Figure 1 about here

330 


\section{Method}

\section{Participants and Procedure}

Approval for this correlational study to examine student reactions to computer-based

334 simulation games was obtained from our university's Institutional Review Board. Participants

335 were students enrolled in an undergraduate logistics and supply chain class in a medium-sized

336 public university in the southeastern part of the United States, and data were collected in a total

337 of 5 classrooms, across two semesters. The team-based simulation game for this study mimics

338 the functionality of operations management software, (e.g., enterprise resource planning, or ERP,

339 systems). Large companies typically rely on these sophisticated and expensive computer

340 systems to manage their business. Available from ERPsimLab HEC Montreal (Léger, Robert,

341 Babin, Pellerin \& Wagner, 2007), the game was developed under the auspices of SAP.

342 SAP provides software to $80 \%$ of the Fortune 500 companies. This particular simulation game is

343 utilized both in university classrooms, and also in businesses, to teach the conceptual foundations

344 of the ERP and to provide specific training on how to use the system. The game is designed to

345 be played by teams of two to four participants. Because the system is complex and requirements

346 differentiated, if team members specialize in certain areas, team performance should improve

347 (Léger et al, 2010).

348 Standard instructions were generated and utilized when introducing the simulation to the

349 students. In the introduction and just before each round of play, students were reminded that it

350 was okay to make errors during the learning process. Consequently, there were no grades linked

351 to actual performance in the simulation. Instead, students received an individual

352 participation grade for being present the day of the simulation play. Moreover, team members

353 did not evaluate each other in any way. During the simulation, students were placed into teams 
Page 17 of 50

354 and introduced to the enterprise resource planning software in a set of rounds. All three rounds

355 of the simulation utilize the same market environment. Each round of play became increasingly

356 more complex. Initially, students conducted pricing and marketing within a market. In the

357 second round, students were required to continually restock via a purchasing function. The

358 students needed to work together to correctly sell product, but not run out before their reordered

359 product arrived. In the third round students also used the SAP system to complete materials

360 requirements planning which, if completed correctly, signaled to purchasing that more product

361 needs to be ordered. In total, students interacted with five different SAP screens to correctly

362 complete the planning process, procurement process and sales process. Furthermore, students

363 had to obtain information from 6 reports to understand their market environment, sell at a profit,

364 and remain stocked with the products that best match the market. So, the game is complex, it

365 simulates customer and vendor behaviors, as well as the passage of time. This is a serious

366 business simulation, without an entertainment aspect, and requires the students to engage in

367 strategic decision making and dynamic problem-solving.

368 Data collection for this study occurred at two distinct time points. The variables that

369 were chosen for this analysis are a subset of a larger survey. This is the sole study resulting from

370 that survey. At the start of the semester, a survey was conducted, collecting information about

371 trait learning goal orientations. At this time, students were randomly assigned to work together

372 in teams. Then, toward the latter part of the semester, the simulation game was introduced.

373 Approximately three weeks of class time was reserved for the students to work together and

374 engage in repetitive rounds of play. After the final round was completed, another survey was

375 administered; this time asking about impressions of knowledge sharing behaviors, transactive

376 memory systems, individual satisfaction levels, and perceived team performance. A total of 131 
377 students participated in the final round of play. Out of that 131, seven students declined

378 permission for their data to be used in the analysis and six records were list-wise deleted because

379 of missing data. This left a total of 118 complete responses. Because of absenteeism, 18 of

380 these 118 students participated in the game alone. This left 100 students working together in 42

381 teams as the basis for our analysis.

\section{Measures}

Learning goal orientation. Learning goal orientation was assessed using 4 items adapted

384 from VandeWalle, 1997. Sample items include: "I enjoy challenging and difficult tasks where

385 I'll learn new skills," and "I often look for opportunities to develop new skills and knowledge."

386 Items were rated on a six-point scale ranging from $1=$ "Strongly Disagree" to 6 = "Strongly

387 Agree". The internal reliability coefficient for learning goal orientation was 0.78 .

Knowledge sharing norms. Knowledge sharing norms was assessed using 10 items

389 adapted from Quigley et al., 2007. Items were rated on a seven-point scale ranging from $1=$ 390 "Almost Never True" to 7 = "Almost Always True." When asked the extent it seemed that "you 391 and your teammates developed a mutual understanding that each other on the team would...", 392 students responded to such sample questions as: "share information on hints when you thought it 393 might help the others on the team," "share information on strategies that seemed to work well," 394 and "go out of your way to help the others on the team with a problem or question." The internal 395 reliability for this measure was 0.96 .

396 Transactive memory systems. Transactive memory systems (TMSs) was adapted from 397 Lewis, 2003. Using 15 items, rated on a 5 point scale ranging from $1=$ "Strongly disagree" to 5 $398=$ "Strongly agree," sample questions include: "Different team members were responsible for 399 expertise in different team areas," and "I have knowledge about an aspect of the exercise that no 
400 other team member has." The measure includes dimensions of team specialization,

401 coordination, and credibility. Internal reliability was 0.85 .

402 Satisfaction with the team. Team satisfaction was adapted from Spector, 1994. Using 4 403 items, rated on a 7 point scale ranging from 1 ="Disagree very much" to $7=$ "Agree very much," 404 sample questions include: "I liked the people I worked with," and "I found I had to work harder 405 because of the incompetence of the people I worked with (reverse scored)." The internal 406 reliability for this measure was 0.72 .

407

Satisfaction with the task. Task satisfaction was adapted from Spector, 1994. Using 5

408 items, rated on a 7 point scale ranging from 1 ="Disagree very much" to $7=$ "Agree very much," 409 sample questions include: "I liked doing the things I did on the simulation game exercise," "The 410 simulation game exercise was enjoyable," and "I felt the simulation game exercise was 411 meaningless (reversed scored)." The internal reliability for this measure was 0.91 .

412 Perceived team performance. Perceived team performance was assessed using 3 items, 413 rated on a 6 point scale ranging from $1=$ "Disagree very much" to $6=$ "Agree very much."

414 Sample questions include: "My team performed very effectively on this exercise," and "My team 415 made a quality decision." The internal reliability for this measure was 0.95 .

416 Actual team performance. Actual team performance is a calculated variable, generated 417 by the ERPsim game. The game simulates revenue and costs based on player decisions.

418 Throughout the game, the players see the financial impact of their actions. At conclusion of each 419 round, a set of financial metrics, such as total sales and gross margin, are calculated and 420 displayed. We chose the natural logarithm of cumulative net income as our performance metric, 421 but the variable remained non-normally distributed with skewness $=-1.45$ and kurtosis $=0.20$.

\section{Analyses}


Page 20 of 50

\section{Aggregation and measurement analyses}

To justify aggregating our individual response data to the team level, we examined

425 proportions of within and between group variance, as well as indicators of rater reliability. We

426 calculated ICC variables to check on the proportion of between and within group variance. The

427 ICC(1) indicates the proportion of variance that is attributable to group membership, while the

428 ICC(2) indicates the reliability of group means (Hox, 2002; Bliese, 2000). To ensure that team

429 member assessments were similar, we computed interrater reliability scores (LeBreton and

430 Senter, 2008). Using the tool from Biemann, Cole, and Voelpel (2012), we calculated the

431 multiple-item estimator of $r_{\mathrm{wg}}(\mathrm{j})$ with a uniform distribution, as well as measure specific

432 distributions.

433 Table 1 contains the results of our analyses, which yielded support for our aggregation 434 decisions. For example, with knowledge sharing norms, we found the following: $\operatorname{mean} r_{\mathrm{wg}(\mathrm{j}) \text {, }}$ 435 uniform $=.87 ; r_{\mathrm{wg}(\mathrm{j}) \text {, slight skew }}=.81 ; \operatorname{ICC}(1)=.30 ; \operatorname{ICC}(2)=.50$, with an $F$ ratio $=2.02, \mathrm{p}<.01$. For 436 transactive memory systems, we found a mean $r_{\mathrm{wg}(\mathrm{j}) \text {, uniform }}=.95 ; r_{\mathrm{wg}(\mathrm{j}) \text {, normal }}=.69 ; \operatorname{ICC}(1)=.29$; $437 \operatorname{ICC}(2)=.49$, with an $F$ ratio $=1.95, \mathrm{p}<.05$. Finally, for perceived team performance, we found 438 the mean $r_{\mathrm{wg}(\mathrm{j}) \text {, uniform }}=.78 ; r_{\mathrm{wg}(\mathrm{j}) \text {, slight skew }}=.69 ; \operatorname{ICC}(1)=.36 ; \operatorname{ICC}(2)=.57$, with an $F$ ratio $=$ $4392.32, \mathrm{p}<.01$.

444 average team size was small at 2.38. Low ICC(2) values can be attributed to small team sizes 445 and, while low ICC(2)s might adversely affect statistical power, they do not preclude the use of 
Page 21 of 50

446 multilevel analytical techniques (Bliese, Maltarich, \& Hendricks, 2018). However, as an

447 additional precaution, we conducted an $r_{\mathrm{wg}(\mathrm{j})}$ sensitivity analysis to make sure these variables

448 truly represent group constructs (Beimann et al., 2012). We eliminated four teams with low $r_{\mathrm{wg}(\mathrm{j})}$

449 uniform scores and reran our analysis. We found little impact on the results and nothing that would

450 alter our substantive conclusions. Consequently, we aggregated data and created our team-level

451 variables.

452 Analytical strategy

453 Our research question involves outcomes at two levels of analysis. At the lowest level,

454 we are interested in the effects of trait learning goal orientations on individual perceptions of

455 team and task satisfaction, (i.e., satisfaction with the team and satisfaction with the task). At the

456 group level, we are interested in the effects of knowledge sharing norms and transactive memory

457 systems on perceptions of team performance and actual team performance, as well as their effect

458 on individual (level-one) perceptions, (i.e., satisfaction with the team and satisfaction with the

459 task). Since our sample size is small, with just 100 observations, we opted to analyze our data in

460 two parts. To analyze our group level variables, we conducted an OLS regression using SAS

461 PROC REG and assessed the mediated, or indirect, effects using PROCESS (Hayes, 2017). To

462 examine our individual level outcomes, we conducted random coefficients modeling using SAS

463 PROC MIXED (Bliese, 2002; Singer, 1998). Our multilevel model contains a second-level

464 mediator. Consequently, we use MSEM and MPLUS version 8 (Muthén \& Muthén, 1998-2017)

465 to assess our mediation paths, as this technique allows for higher level outcome variables

466 (Preacher, Zyphur, \& Zhang, 2010). We used a Monte Carlo Method for Assessing Mediation

467 (MCMAM) to create confidence intervals for the indirect effects (Selig \& Preacher, 2008). Prior

468 to conducting our multilevel analysis, we needed to determine the best fitting model, so we 
469 followed the build-up procedure from Hox (2002). Using this method, we looked to see if the 470 predictors, random intercepts, random slopes, and/or cross-level interactions were helpful with

471 model fit. After this analysis, we determined that, for both satisfaction with the team and

472 satisfaction with the task, our best fitting multilevel model, as written below, has a single level-1

473 predictor, random intercepts, two level-2 predictors and fixed slopes. $\beta_{1 j}=\gamma_{10}$

Simplified model:

$Y i j=\gamma_{00}+\gamma_{01}($ KSNorms $)+\gamma_{02}(T M S)+\gamma_{10}(T M L G O)+e_{i j}+u_{0 j}$

Our model does not include cross-level interactions, and we are not assessing an

individual's standing relative to his or her group. As such, we opted against group-mean

482 centering. However, to facilitate interpretation of the intercepts, we did grand-mean center our 483 predictor variables.

\section{Results}

Table 2 provides the means, standard deviations, reliabilities and correlations for the 486 study variables. The information in 2.1 pertains to the individual level of analysis. The 487 information in 2.2 pertains to the team-level variables.

Multilevel examination of individual outcome variables

In order to test our hypotheses, we first had to ensure that significant team variance in in

493 our dependent variables existed. Two null models were evaluated. The interclass correlation

494 (ICC) for team satisfaction indicated that the $34 \%$ of the variance is between teams and $66 \%$ 
Page 23 of 50

495 within teams. The interclass correlation (ICC) for task satisfaction indicated that the $33 \%$ of the

496 variance is between teams and $67 \%$ within teams. Both ICCs provide strong support for

497 continuing with our multilevel analyses (Hox, 2002; Bliese, 2000).

498

499

Insert Table 3 about here

500

501

As depicted in Table 3, the first model presents information about the null model. The

502 second model presents the impact of adding our individual-level predictor, trait learning goal

503 orientation. Model 3 of this table includes the individual-level predictor and both team-level

504 predictors, knowledge sharing norms and transactive memory systems. Model 3 was employed

505 to test our hypotheses.

506

According to hypothesis 1a, we expect to find a positive relationship between knowledge

507 sharing norms and both the satisfaction variables. Looking first at the fixed effects, we see that

508 the relationship between knowledge sharing norms and satisfaction with the team is positive and

509 significant $(\hat{\gamma}=.33, p<.01)$, but the relationship between knowledge sharing norms and

510 satisfaction with the task is not significant $(\hat{\gamma}=.09$, n.s. $)$. The relationship between transactive

511 memory systems and satisfaction with the team is significant and positive $(\hat{\gamma}=.57, p<.01)$. as is

512 the relationship between transactive memory systems and satisfaction with the $\operatorname{task}(\hat{\gamma}=1.43$,

$513 p<.01)$. Hypotheses 4 states that individual trait learning goal orientation would be positively

514 related to both satisfaction with the task and satisfaction with the team. The relationship between

515 learning goal orientation and satisfaction with the task is positive and significant $(\hat{\gamma}=.49$,

$516 p<.05)$. However, the relationship between trait learning goal orientation and satisfaction with

517 the team is not significant $(\hat{\gamma}=.01, n . s$.$) . Therefore, hypothesis 4$ is only partially supported. 

Looking at the random part of our model, for team satisfaction we find that knowledge 519 sharing norms and transactive memory systems explains the variance in team intercepts, $\mathrm{ICC}=$ 5200.00 . The combination of individual trait learning goal orientation, team knowledge sharing 521 norms, and team transactive memory systems explains most of the intercept variance in task 522 satisfaction, ICC $=0.04$. However, a significant amount of variance remains unexplained within 523 teams for both outcomes. The level-1 variance for satisfaction with the team is $\left(\sigma^{2}=.40, p<.01\right)$. 524 The level-1 variance for satisfaction with the task is $\left(\sigma^{2}=1.26, p<.01\right)$. This makes sense, as 525 other factors, such as individual differences, might affect an individual's satisfaction level. 526 To evaluate the overall impact of including the level-2 predictors, we looked at the 527 analysis from a model fit perspective. We evaluated the difference in -2 Log Likelihood between 528 the model with the individual predictor only and the final model, which included our two team 529 level predictors. For the satisfaction with the team variable, we found a significant decrease in 530 deviance for the final model $\left(\chi^{2}\right.$ statistics $\left.35.1, p<.01\right)$. A similar result was noted for satisfaction 531 with the task, with an overall significant improvement in model fit $\left(\chi^{2}\right.$ statistics $\left.20.6, p<.01\right)$.

532 These results indicate that our level-2 predictors explain a significant amount of variance in our 533 model.

534 According to hypotheses 3, we expected team transactive memory systems to mediate the 535 positive relationships between knowledge sharing norms and our level-1 satisfaction outcome 536 variables. To assess our mediation paths, we used MPLUS version 8 (Muthén \& Muthén, 1998537 2017) and used a Monte Carlo Method for Assessing Mediation (MCMAM) to create confidence 538 intervals for the indirect effects (Selig \& Preacher, 2008). Confidence intervals were set to $95 \%$ 539 and bootstrapping was conducted 20,000 times. Results indicate a positive relationship between 540 knowledge sharing norms and satisfaction with the team; this relationship is mediated by 
Page 25 of 50

541 transactive memory systems $[(\beta=0.07, p<0.05,(C I 95 \%: 0.019,0.129)]$. However, the

542 mediated relationship between knowledge sharing norms, transactive memory systems and

543 satisfaction with the task is not significant $[(\beta=0.07, n . s .,(C I 95 \%:-0.005,0.149)]$, therefore

544 hypothesis 1a and hypothesis 3 are only partially supported.

545 Analysis of group level variables

546 To assess the relationships between our team-level variables, we used a regression-based

547 path analysis known as conditional process modeling (Hayes, 2017). This technique employs

548 nonlinear bootstrapping (Preacher, Rucker, \& Hayes, 2007) to evaluate the effect of a causal

549 variable on an outcome through one or more intermediary variables, (i.e., an indirect or mediated

550 effect). In this part of our analysis, we examine the indirect effects of knowledge sharing norms

551 on perceived team performance and actual team performance through the development of

552 specialized team cognitions, (i.e., transactive memory systems). Because we hypothesized that

553 transactive memory systems are the result of knowledge sharing norms, in step one we examine

554 the direct effect of knowledge sharing norms on transactive memory systems. In step two, we

555 assess the direct effect of knowledge sharing norms on the team performance variables. In the

556 third step, we enter in the effects of transactive memory systems and assess the mediation paths.

557 After each step, we assess model fit using $F$-values and $R^{2}$. Results from steps 1 through 3 are

558 shown in Table 4.

559

560

Insert Table 4 about here

561

562

In step 1, overall model fit results were acceptable at $(F(1,40)=17.05, p<.01)$ with $30 \%$

563 of the variance in transactive memory systems explained. Knowledge sharing norms are a 
564 significant predictor of transactive memory systems, with $(\beta=.55, p<.01)$. In step 2 , looking at 565 perceived team performance, model fit results were also acceptable at $(F(1,40)=19.37, p<.01)$

566 with $33 \%$ of the variance in perceived team performance explained. Knowledge sharing norms 567 was a significant predictor of perceived team performance, with $(\beta=.57, p<.01)$. However, also 568 in step 2, looking at actual team performance, model fit results were poor at $(F(1,40)=.09$, n.s. $)$ 569 with none of the variance in actual team performance explained. Knowledge sharing norms was 570 not a significant predictor, with $(\beta=.05$, n.s. $)$. In step 3 , looking at perceived team performance, 571 model fit results remain at acceptable levels with $(F(2,39)=29.32, p<.01)$ with $60 \%$ of the 572 variance in perceived team performance explained. In this step, transactive memory systems was 573 a significant predictor, with $(\beta=.63, p<.01)$, while knowledge sharing norms approached, but 574 did not reach statistical significance with $(\beta=.23, p<.10)$. For actual team performance, model 575 fit results were again very poor at $(F(2,39)=1.00, n . s$.$) with only 5 \%$ of the variance in actual 576 team performance explained. Neither of the predictors were significant, with knowledge sharing 577 norms at $(\beta=-0.09$, n.s. $)$, and transactive memory systems at $(\beta=.26$, n.s. $)$.

$578 \quad$ After running the basic regression models, we employed process modeling and 579 bootstrapping techniques to assess the conditional indirect paths. Because we did not find 580 statistical significance with our actual team performance variable, we focused on perceived team 581 performance. Bootstrapping was invoked 5,000 times. Using $p$-values and biased-corrected 582 bootstrapped confidence intervals less than .05 as our guide, results indicate that the transactive 583 memory systems variable serves as statistically significant mediating mechanism between the 584 focal predictor (knowledge sharing norms) and the outcome variable (perceived team 585 performance). The mediated pathway from knowledge sharing norms to perceived team 586 performance via transactive memory systems was significant with $[(B=0.34, p<.05) ;(C I=0.19$, 
Page 27 of 50

587 0.51)]. Because we did not find statistical significance with our actual team performance

588 variable, these results lend partial support to hypothesis $1 \mathrm{~b}$, which states that knowledge sharing

589 norms will be positively related to a) perceived team performance and b) actual team

590 performance. The results also lend partial support to hypothesis 3 , which states that transactive

591 memory systems will mediate the relationship between knowledge sharing norms and a)

592 perceived team performance and b) actual team performance.

593 In sum, our results indicate that, at the individual level, trait learning goal orientation is

594 related to satisfaction with the task, but not to satisfaction with the team. At the team level,

595 knowledge sharing norms is positively and significantly related to satisfaction with the team, but

596 not satisfaction with the task, while transactive memory systems has a significant and positive

597 effect on both satisfaction with the team and satisfaction with the task. Transactive memory

598 systems partially mediate the relationship between knowledge sharing norms and satisfaction

599 with the team and fully mediate the relationship between knowledge sharing norms and

600 perceived team performance. We found no significant predictive relationships to actual team

601 performance.

602

\section{Discussion}

603 Our results reveal an interesting pattern of outcomes. Drawing on the framework from

604 the IMOI model, we see that, as an input variable, higher levels of learning goal orientation led 605 to higher levels of satisfaction with the task. This makes sense, as a person intent on mastering 606 the material would embrace the challenge of the simulation game, and see the exercise as a way 607 to build personal competencies. This finding is congruent with other studies utilizing computer608 based simulation games. For example, researchers looking at ways to enhance learning in 609 workforce training have adopted an active learning approach. In this methodology, instructional 
610 design components specifically encourage trainees to adopt mastery orientations. Errors are

611 framed as learning opportunities, and trainees are encouraged to explore and experiment with the

612 computerized task. Although immediate performance suffers, deeper learning patterns are

613 achieved through this technique and that deeper learning transfers more readily to the job (Bell \&

614 Kozlowski, 2009). While individual learning goal orientation had a positive effect on

615 satisfaction with the task, we found no statistically significant effect between learning goal

616 orientations and satisfaction with the team. In other words, while the students focused on

617 mastering the material enjoyed the simulation game more, the positive effect did not extend to

618 their teammates. Perhaps, these students were engrossed in their own cognitions and not as

619 engaged in team-related communications. This was not expected and would be a fruitful area for 620 more research.

621 The variables that had the most explanatory effect in our model were related to social

622 exchange and interactions between teammates. In our model, we cannot explain the origin of

623 knowledge sharing behaviors. Those were not explicitly encouraged during the exercise.

624 However, consistent with the predictions of social exchange theory (Cropanzano et al., 2017),

625 when teams engaged in reciprocal knowledge exchange behaviors and established norms for

626 knowledge sharing, the students were happier with their teammates. Moreover, and again

627 consistent with the IMOI model and social exchange (Cropanzano et al., 2017; Ilgen et al.,

628 2005), through repetitive iterations of team processing, these knowledge-sharing norms led to the

629 establishment of transactive memory systems. As transactive memory systems were developed,

630 the team thought they performed better, they liked the simulation game more, and they

631 appreciated each other more. While we did not find a relationship to objective team

632 performance, these affective outcomes might speak to the willingness of the students to engage 
Page 29 of 50

633 in additional future coursework or continue to work with their peers in future team settings.

634 Certainly, reporting a positive team experience would be beneficial as these students begin the 635 job search and begin careers in organizations. While our study was confined to a computerized 636 simulation game, the benefits of encouraging achievement motivations and reciprocal knowledge 637 sharing behaviors within teams would extend to more traditional group-based projects as well. 638 Implications for Teaching 639 This study illustrates the potency of simulation games to cultivate behaviors that could 640 lead to the development of team competencies. We found that knowledge sharing behaviors led 641 to the development of specialized team cognitions. In this way, by lessening the cognitive load 642 on any one person, participants not only enjoyed the learning task more, but they also enjoyed 643 working with each other. This enjoyment was evidenced not only by the satisfaction variables 644 but also through enhanced perceptions of team performance. In the context of an undergraduate 645 game, perceptions of team performance would likely be predictive of a willingness to engage in 646 future team interactions. A positive experience, lending itself to future team engagements would 647 likely lead to the development of team competencies, competencies that are so valuable to future 648 employers. Individuals' learning goal orientations, on the other hand, led to an enhanced sense 649 of satisfaction with the task, but not necessarily to an appreciation of one's teammates. Since 650 knowledge sharing behaviors can be encouraged and learning goal orientations are malleable, the 651 results of this study should be of interest to educators, (Bell \& Kozlowski, 2009; Steele-Johnson 652 et al., 2000).

653 Learning goal orientations can be encouraged through the use of instructional design 654 techniques that encourage self-regulatory learning, e.g. encouraging exploration, 655 experimentation, and positive framing of errors (Bell \& Kozlowski, 2009). To facilitate norms 
656 for knowledge sharing, the students should be encouraged to work together, ask each other 657 questions, and converse during the simulation rounds. By de-emphasizing evaluations and 658 stressing the development of abilities, students should adopt "state" learning goal orientations 659 (Steele-Johnson et al., 2000). Instead of seeing a question and answer exchange as a potential 660 exposure of incompetence, it should frame the knowledge exchange as a way for all members on 661 the team to benefit. Moreover, it should encourage all members of the team to engage in the 662 simulation game.

663 During the debriefing, instructors should remind team members of how their ability to 664 share understandings and their mental representations of the team's task environment generally 665 reduced the mental load on any one team member. Thus, through reflection, this should 666 reinforce the concept that no one person can do it all; moreover, when knowledge sharing occurs 667 among team members, it makes the learning task much more enjoyable. In this way, through the 668 use of simulation games, educators can emphasize critical thinking and problem-solving skills, 669 while also encouraging the development of behaviors that lead to team competencies.

670 Limitations and Suggestions for Future Research

Our study was a correlational study. We captured survey information from students

672 enrolled in a logistics and supply chain class in a single, medium-sized university. To gain more 673 insight into the formation of student team structures and cognitions, future studies should include 674 control groups and experimental conditions. Future studies might also look at the antecedents of 675 team knowledge sharing norms, as well as the effects of encouraging learning goal orientations 676 in tandem with knowledge sharing behaviors. None of our independent variables were predictive 677 of actual team performance. This was an unexpected finding and could be due to our research 678 design. Before we measured performance, we allowed the students several rounds of play over 
679 the course of three weeks. During this time, some of the students may have had time to develop

680 more advanced levels of skill, while others may not. Also, we may not have captured the

681 variables relating to actual performance. Another explanation might be related to statistical

682 power. A post-hoc power analysis suggests that the number of teams in our sample size was

683 small. However, even with a small sample size, we found significant effects in support of prior

684 research and a-priori theorized relationships. In the future, studies might compare student

685 reactions from a computer-based simulation game with those from other, more traditional, group

686 projects, such as research reports or in-class presentations. Also, longitudinal studies should

687 follow students through their respective program completions and see if the experiential nature

688 of the simulation games is helpful for upper-level course work, as well as future job

689 opportunities and future job performance.

690 It is also worth noting that, in our study, knowledge sharing norms led to the formation of

691 transactive memory systems. Our participants were novices and most likely volunteered to

692 acquire, rather than share, respective areas of expertise. However, with a more professional

693 sample, the sequencing of transactive memory systems and norms for knowledge sharing might

694 be reversed, i.e., having an established TMS would lead to knowledge sharing, which would, in

695 turn, lead to better team performance (Choi, Lee, \& Yoo, 2010)

696

\section{Conclusion}

697

The goal of our study was to advance an understanding of determinants of student

698 success in computer-based simulation games, at the individual and team levels. Consistent with

699 theories of achievement motivations, our findings suggest that students with higher levels of trait

700 learning goal orientations are intent on the game itself, and they enjoyed the learning exercise.

701 From a social exchange perspective, we find that team member interactions and reciprocal 
702 knowledge exchanges were instrumental in the development of specialized team cognitions, or 703 transactive memory systems. In our study, when teams formed transactive memory systems, 704 they liked working on the game, they perceived that they were performing better on the game, 705 and they enjoyed their teammates more. Future studies should look at the factors which are 706 instrumental in encouraging team knowledge sharing norms, as well as the effects of 707 encouraging learning goal orientations in tandem with knowledge sharing behaviors. 
709

710

711

712

713

714

715

716

717

718

719

720

721

722

723

724

725

726

727

728

729

730

731

\section{References}

Akgün, A. E., Byrne, J., Keskin, H., Lynn, G. S., \& Imamoglu, S. Z. (2005). Knowledge networks in new product development projects: A transactive memory perspective. Information \& Management, 42(8), 1105-1120. doi:10.1016/j.im.2005.01.001

Bachrach, D. G., Lewis, K., Kim, Y., Patel, P. C., Campion, M. C., \& Thatcher, S. M. B. (2019). Transactive memory systems in context: A meta-analytic examination of contextual factors in transactive memory systems development and team performance. Journal of Applied Psychology, 104(3), 464-493. doi:10.1037/ap10000329

Bartol, K. M., Liu, W., Zeng, X., \& Wu, K. (2009). Social exchange and knowledge sharing among knowledge workers: The moderating role of perceived job security. Management and Organization Review, 5(2), 223-240. doi:10.1111/j.1740-8784.2009.00146.x

Bedwell, W. L., Fiore, S. M., \& Salas, E. (2014). Developing the future workforce: An approach for integrating interpersonal skills into the MBA classroom. Academy of Management Learning \& Education, 13(2), 171-186. doi:10.5465/amle.2011.0138

Bell, B. S., Kanar, A. M., \& Kozlowski, S. W. (2008). Current issues and future directions in simulation-based training in North America. The International Journal of Human Resource Management, 19(8): 1416-1434. doi:10.1080/09585190802200173

Bell, B. S., \& Kozlowski, S. W. J. (2002). Goal orientation and ability: Interactive on selfefficacy, performance, and knowledge. Journal of Applied Psychology, 87(3): 497-505. doi:10.1037//0021-9010.873.3.497

Bell, B. S., \& Kozlowski, S. W. J. (2008). Active learning: effects of core training design elements on self-regulatory processes, learning, and adaptability. Journal of Applied Psychology, 93(2): 296-316. doi:10.1037/0021-9010.93.2.296.x 
732 Bell, B. S., \& Kozlowski, S. W. J. (2009). Toward a theory of learner-centered training design:

733

734

735

736

737

738

739

740

741

742

743

744

745

746

747

748

749

750

751

752
An integrative framework of active learning [Electronic version]. In S. W. J. Kozlowski, \& E. Salas (Eds.), Learning, training, and development in organizations: (pp. 263-300). New York: Routledge.

Biemann, T., Cole, M. S., \& Voelpel, S. (2012). Within-group agreement: On the use (and misuse) of rWG and $\mathrm{rWG}(\mathrm{J})$ in leadership research and some best practice guidelines. The Leadership Quarterly, 23(1), 66-80. doi:10.1016/j.leaqua.2011.11.006

Blau, P. M. (1964). Justice in Social Exchange. Sociological Inquiry, 34(2), 193-206. doi:10.1111/j.1475-682X.1964.tb00583.x

Bliese, P. D. (2000). Within-group agreement, non-independence, and reliability: Implications for data aggregation and analysis. In K. J. Klein, \& S. W. Kozlowski (Eds.), Multilevel theory, research, and methods in organizations: Foundations, extensions, and new directions: (pp. 349-381). San Francisco: Jossey-Bass Inc.

Bliese, P.D. (2002). Multilevel random coefficient modeling in organizational research. Examples using SAS and S-PLUS. In F. Drasgow, \& N. Schmitt (Eds.), Measuring and Analyzing Behavior in Organizations: (pp. 401-405). San Francisco: Jossey-Bass Inc.

Bliese, P. D., Maltarich, M. A., \& Hendricks, J. L. (2018). Back to basics with mixed-effects models: Nine take-away points. Journal of Business and Psychology, 33(1), 1-23. doi:10.1007/s 10869-017-9491-z

Brown, K. G. (2001). Using computers to deliver training: Which employees learn and why? Personnel Psychology, 54(2), 271-296. doi:10.1111/j.1744-6570.2001.tb00093.x 
Page 35 of 50

753 Cannon-Bowers, J. A., Salas, E., \& Converse, S. (1993). Shared mental models in expert team 754 decision making. In N. J. Castellan, Jr. (Ed.), Individual and group decision making:

755 Current issues. (pp. 221-246). Hillsdale, NJ: Lawrence Erlbaum Associates, Inc.

756 Chen, G., Donahue, L. M., \& Klimoski, R. J. (2004). Training undergraduates to work in 757 758 organizational teams. Academy of Management Learning \& Education, 3(1), 27-40. doi:10.5465/AMLE.2004.12436817

Choi, S. Y., Lee, H., \& Yoo, Y. (2010). The impact of information technology and transactive memory systems on knowledge sharing, application, and team performance: A field study. MIS Quarterly, 34(4), 855-870. doi:10.2307/25750708

762 763

764

765

766

767

768

769

770

771

772

773

774

Cropanzano, R., Anthony, E. L., Daniels, S. R., \& Hall, A. V. (2017). Social exchange theory: A critical review with theoretical remedies. The Academy of Management Annals, 11(1), 479-516. doi:10.5465/annals.2015.0099

Cropanzano, R., \& Mitchell, M. S. (2005). Social exchange theory: An interdisciplinary review. Journal of Management, 31(6), 874-900. doi:10.1177/0149206305279602

DeChurch, L. A., \& Mesmer-Magnus, J. R. (2010). The cognitive underpinnings of effective teamwork: a meta-analysis. Journal of Applied Psychology, 95(1), 32. doi: $10.1037 / \mathrm{a} 0017328$

De Dreu, C. K. W., Nijstad, B. A., \& van Knippenberg, D. (2008). Motivated information processing in group judgment and decision making. Personality \& Social Psychology Review, 12(1), 22-49. doi:10.1177/1088868307304092

DeShon, R. P., Kozlowski, S. W., Schmidt, A. M., Milner, K. R., \& Wiechmann, D. (2004). A multiple-goal, multilevel model of feedback effects on the regulation of individual and 
775

776

777

778

779

780

781

782

783

784

785

786

787

788

789

790

791

792

793

794

795

team performance. Journal of Applied Psychology, 89(6): 1035-1056. doi:10.1037/00219010.89.6.1035

Dierdorff, E. C., \& Ellington, J. K. (2012). Members matter in team training: Multilevel and longitudinal relationships between goal orientation, self-regulation, and team outcomes. Personnel Psychology, 65(3): 661-703. doi:10.1111/j.1744-6570.2012.01255.x

Dierdorff, E. C., Surface, E. A., Harman, R. P., Kemp Ellington, J., \& Watson, A. M. (2018). Ebb and flow of dispositional goal orientations: Exploring the consequences of withinperson variability. Journal of Business and Psychology. (pp. 1-18). doi:10.1007/s10869018-9559-4

Dirks, K. T., \& Ferrin, D. L. (2001). The role of trust in organizational settings. Organization Science, 12(4), 450-467. doi:10.1287/orsc.12.4.450.10640

Dragoni, L. (2005). Understanding the emergence of state goal orientation in organizational work groups: The role of leadership and multilevel climate perceptions. Journal of Applied Psychology, 90(6): 1084-1095. doi:10.1037/0021-9010.90.6.1084

Dweck, C. S. (1986). Motivational processes affecting learning. American Psychologist, 41(10): 1040-1048. doi:10.1037/0003-066X.41.10

Eisenberger, R., Armeli, S., Rexwinkel, B., Lynch, P. D., \& Rhoades, L. (2001). Reciprocation of perceived organizational support. Journal of Applied Psychology, 86(1), 42-51. doi:10.1037/0021-9010.86.1.42

Faria, A. J. (1998). Business simulation games: Current usage levels—An update. Simulation \& Gaming, 29(3): 295-308. doi:10.1177/1046878198293002 
Page 37 of 50

796 Faria, A. J., Hutchinson, D., Wellington, W. J., \& Gold, S. (2009). Developments in business 797 798 gaming: A review of the past 40 years. Simulation \& Gaming, 40(4): 464-487. doi:10.1177/1046878108327585

Faria, A. J., \& Wellington, W. J. (2004). A survey of simulation game users, former-users, and never-users. Simulation \& Gaming, 35(2): 178-207. doi: 10.1177/1046878104263543

801 Fiore, S. M., Salas, E., \& Cannon-Bowers, J. A. (2001). Group dynamics and shared mental 802 803 804 805 806 model development. In M. London (Ed.), How people evaluate others in organizations. (pp. 309-336). Mahwah, NJ: Lawrence Erlbaum Associates Publishers.

Fisher, S. L., \& Ford, J. K. (1998). Differential effects of learner effort and goal orientation on two learning outcomes. Personnel Psychology, 51(2), 397-420. doi:10.1111/j.17446570.1998.tb00731.x

807 Gockel, C., Robertson, R., \& Brauner, E. (2013). Trust your teammates or bosses? Differential 808 effects of trust on transactive memory, job satisfaction, and performance. Employee 809 Relations, 35(2), 222-242. doi:10.1108/01425451311287880

810 Hayes, A. F. (2017). Introduction to mediation, moderation, and conditional process anlaysis: a 811 regression-based approach. New York: Guilford Publications.

812 Hays, R. T. (2005). The effectiveness of instructional games: A literature review and discussion 813 (Tech. Rep. No 2005-004). Orlando, FL: Naval Air Warfare Center, Training Systems 814 Division.

815 He, J., Butler, B. S., \& King, W. R. (2007). Team cognition: Development and evolution in 816 software project teams. Journal of Management Information Systems, 24(2), 261-292. doi:10.2753/MIS0742-1222240210 
818 Hinsz, V. B., Tindale, R. S., \& Vollrath, D. A. (1997). The emerging conceptualization of groups 819 as information processors. Psychological Bulletin, 121(1): 43-64. doi:10.1037/00332909.121.1.43

821 Hollingshead, A. B. (1998). Retrieval processes in transactive memory systems. Journal of 822 Personality and Social Psychology, 74(3), 659-671. doi:10.1037/0022-3514.74.3.659

823 Hox, J. (2002). Multilevel analysis techniques and applications. Mahwah, NJ: Lawrence 824 Erlbaum Associates Publishers.

825 Ilgen, D. R., Hollenbeck, J. R., Johnson, M., \& Jundt, D. (2005). TEAMS IN 826 ORGANIZATIONS: From Input-Process-Output Models to IMOI Models. Annual review of psychology, 56(1), 517-543. doi:10.1146/annurev.psych.56.091103.070250

828 Janz, B. D., Colquitt, J. A., \& Noe, R. A. (1997). Knowledge worker team effectiveness: The 829 830 role of autonomy, interdependence, team development, and contextual support variables.

831 Jarvenpaa, S. L., \& Majchrzak, A. (2008). Knowledge collaboration among professionals 832 833 protecting national security: Role of transactive memories in ego-centered knowledge networks. Organization Science, 19(2), 260-276. doi:10.1287/orsc.1070.0315

834 Jehn, K. A., Northcraft, G. B., \& Neale, M. A. (1999). Why differences make a difference: A 835 field study of diversity, conflict, and performance in workgroups. Administrative Science 836 Quarterly, 44(4), 741-763. doi:10.2307/2667054

837 Kanawattanachai, P., \& Yoo, Y. (2007). The impact of knowledge coordination on virtual team 838 performance over time. MIS Quarterly, 31(4), 783-808. doi:10.2307/25148820 
Page 39 of 50

839 Klein, H. J., Noe, R. A., \& Wang, C. (2006). Motivation to learn and course outcomes: The

840

841

\section{2}

843

844

845

846

847

848

849

850

851

852

853

854

855

856

857

858

859

860

861 impact of delivery mode, learning goal orientation, and perceived barriers and enablers. Personnel Psychology, 59(3), 665-702. doi:10.1111/j.1744-6570.2006.00050.x

Klimoski, R., \& Mohammed, S. (1994). Team mental model: Construct or metaphor? Journal of Management, 20(2): 403. doi:10.1177/014920639402000206

Kozlowski, S. W. J., \& Bell, B. S. (2008). Team learning, development, and adaptation. In Sessa \& M. London (Eds.), Group Learning: Understanding, improving and assessing how groups learn in organizations (pp. 15-44). New York, NY: Taylor \& Francis Group.

Kozlowski, S. W. J., \& Bell, B. S. (2013). Work groups and teams in organizations: Review update. In N. Schmitt, \& S. Highhouse (Eds.), Handbook of psychology: Vol. 12. Industrial and organizational psychology (2 ${ }^{\text {nd }}$ ed.): 412-469. Hoboken, NJ: Wiley.

Kozlowski, S. W. J., \& DeShon, R. P. (2004). A psychological fidelity approach to simulationbased training: Theory, research and principles. In E. Salas, L. R. Elliott, S. G. Schflett, \& M. D. Coovert (Eds.), Scaled worlds: Development, validation, and applications: (pp. 75-99). Burlington, VT: Ashgate Publishing.

Kozlowski, S. W. J. \& Klein, K. J. (2000). A Multilevel Approach to Theory and Research in Organizations. In K. J. Klein, \& S. W. Kozlowski (Eds.), Multilevel theory, research, and methods in organizations: Foundations, extensions, and new directions: (pp. 3-90). San Francisco: Jossey-Bass Inc.

LeBreton, J. M., \& Senter, J. L. (2008). Answers to 20 questions about interrater reliability and interrater agreement. Organizational research methods, 11(4), 815-852. doi: $10.1177 / 1094428106296642$ 
862 Léger, P.-M., Robert, J., Babin, G., Lyle, D., Cronan, P., \& Charland, P. (2010). ERP simulation 863 game: A distribution game to teach the value of integrated systems, Developments in Business Simulation and Experiental Learning, 37, 329-334.

865 Léger, P.-M., Robert, J., Babin, G., Pellerin, R. and Wagner, B. (2007). ERPsim, ERPsim Lab, 866 HEC Montréal, Montréal, Qc.

867 Lewis, K. (2003). Measuring transactive memory systems in the field: scale development and 868 validation. Journal of Applied Psychology, 88(4), 587. doi:10.1037/0021-9010.88.4.587

869 Lewis, K. (2004). Knowledge and Performance in Knowledge-Worker Teams: A Longitudinal 870 Study of Transactive Memory Systems. Management science, 50(11), 1519-1533. doi:10.1287/mnsc. 1040.0257

Lewis, K., \& Herndon, B. (2011). Transactive memory systems: Current issues and future research directions. Organization Science, 22(5), 1254-1265. doi:10.1287/orsc.1110.0647

874 Lewis, K., Lange, D., \& Gillis, L. (2005). Transactive memory systems, learning, and learning 875 transfer. Organization Science, 16(6): 581-598. doi:10.1287/orsc.1050.0143

Liang, D. W., Moreland, R., \& Argote, L. (1995). Group versus individual training and group performance: The mediating factor of transactive memory. Personality and Social Psychology Bulletin, 21(4), 384-393. doi:10.1177/0146167295214009

Lovelace, K. J., Eggers, F., \& Dyck, L. R. (2016). I Do and I Understand: Assessing the Utility of Web-Based Management Simulations to Develop Critical Thinking Skills. Academy of

882 Marlow, S. L., Salas, E., Landon, L. B., \& Presnell, B. (2016). Eliciting teamwork with game 883 884 attributes: A systematic review and research agenda. Computers in Human Behavior, 55(Part A), 413-423. doi:10.1016/j.chb.2015.09.028 
885 Marlow, S. L., Lacerenza, C. N., Paoletti, J., Burke, C. S., \& Salas, E. (2018). Does team

886

887

888

889

890

891

892

893

894

895

896

897

898

899

900

901

902

903

904

905

906

907

communication represent a one-size-fits-all approach?: A meta-analysis of team communication and performance. Organizational Behavior \& Human Decision Processes, 144, 145-170. doi:10.1016/j.obhdp.2017.08.001

Mathieu, J. E., Hollenbeck, J. R., van Knippenberg, D., \& Ilgen, D. R. (2017). A century of work teams in the Journal of Applied Psychology. Journal of Applied Psychology, 102(3), 452467. doi:10.1037/ap10000128

Mesmer-Magnus, J. R., \& DeChurch, L. A. (2009). Information sharing and team performance: A meta-analysis. Journal of Applied Psychology, 94(2): 535-546. doi:10.1037/a0013773

Michinov, E., Olivier-Chiron, E., Rusch, E., \& Chiron, B. (2008). Influence of transactive memory on perceived performance, job satisfaction and identification in anaesthesia teams. British journal of anaesthesia, 100(3), 327-332. doi:https://doi.org/10.1093/bja/aem404

Mohammed, S., \& Dumville, B. C. (2001). Team mental models in a team knowledge framework: Expanding theory and measurement across disciplinary boundaries. Journal of Organizational Behavior, 22(2), 89-106. doi:10.1002/job.86

Molm, L. D., Takahashi, N., \& Peterson, G. (2000). Risk and trust in social exchange: An experimental test of a classical proposition. American Journal of Sociology, 105(5), 1396-1427. doi:10.1086/210434

Muthén, L., \& Muthén, B. (1998-2017). Mplus User's Guide (Eighth ed.). Los Angeles, CA: Muthén \& Muthén.

National Association of Colleges and Employers. (2016). Job Outlook 2016: The attributes employers want to see on new college graduates' resumes. 
https://www.naceweb.org/career-development/trends-and-predictions/job-outlook-2016attributes-employers-want-to-see-on-new-college-graduates-resumes/

Nijstad, B. A., \& De Dreu, C. K. W. (2012). Motivated information processing in organizational teams: Progress, puzzles, and prospects. Research in Organizational Behavior, 32, 87-

Payne, S. C., Youngcourt, S. S., \& Beaubien, J. M. (2007). A meta-analytic examination of the

Pearsall, M. J., \& Ellis, A. P. (2006). The effects of critical team member assertiveness on team performance and satisfaction. Journal of Management, 32(4), 575-594. doi: $10.1177 / 0149206306289099$

Poortvliet, P. M., \& Darnon, C. (2010). Toward a More Social Understanding of Achievement Goals: The Interpersonal Effects of Mastery and Performance Goals. Current Directions in Psychological Science, 19(5), 324-328. Retrieved from www.jstor.org/stable/41038594

Porter, C. O. L. H. (2012). A multilevel, multiconceptualization perspective of goal orientation in teams. In V. Sessa, \& M. London (Eds.), Work group learning: (pp. 173-198): Psychology Press.

Porter, C. O. L. H., Franklin, D. A., Swider, B. W., \& Yu, R. C.-F. (2016). An exploration of the interactive effects of leader trait goal orientation and goal content in teams. Leadership Quarterly, 27(1): 34-50. doi: 10.1016/j.leaqua.2015.09.004

Preacher, K. J., Rucker, D. D., \& Hayes, A. F. (2007). Addressing moderated mediation hypotheses: Theory, methods, and prescriptions. Multivariate behavioral research, 42(1), 185-227. doi:10.1080/00273170701341316 
931 Preacher, K. J., Zyphur, M. J., \& Zhang, Z. (2010). A general multilevel SEM framework for 932 assessing multilevel mediation. Psychological Methods, 15(3): 209-233.

934 doi:10.1037/a0020141

Quigley, N. R., Tesluk, P. E., Locke, E. A., \& Bartol, K. M. (2007). A Multilevel investigation of the motivational mechanisms underlying knowledge sharing and performance. Organization Science, 18(1): 71-88. doi:10.1287/orsc.1060.0223

Ren, Y., \& Argote, L. (2011). Transactive memory systems 1985-2010: An integrative framework of key dimensions, antecedents, and consequences. The Academy of Management Annals, 5(1), 189-229. doi:10.1080/19416520.2011.590300

Ritter, B. A., Small, E. E., Mortimer, J. W., \& Doll, J. L. (2018). Designing Management

949 Salas, E., Shuffler, M. L., Thayer, A. L., Bedwell, W. L., \& Lazzara, E. H. (2015).

950 Understanding and improving teamwork in organizations: A scientifically based practical 951 guide. Human Resource Management, 54(4): 599-622. doi:10.1002/hrm.21628 
952 Salas, E., Wildman, J. L., \& Piccolo, R. F. (2009). Using simulation-based training to enhance 953 management education. Academy of Management Learning \& Education, 8(4): 559-573. doi:10.5465/amle.2009.47785474

955 Selig, J. P., \& Preacher, K. J. (2008), June. Monte Carlo method for assessing mediation: An 956 interactive tool for creating confidence intervals for indirect effects [Computer software].

958 Singer, J.D. (1998). Using SAS PROC MIXED to Fit Multilevel Models Hierarchical Models, 959 and Individual Growth Models. Journal of Educational and Behavioral Statistics, Vol. 960 23, No. 4. (Winter, 1998), pp. 323-355.

961 Sitzmann, T. (2011). A meta-analytic examination of the instructional effectiveness of 962 computer-based simulation games. Personnel Psychology, 64(2): 489-528. doi:10.1111/j.1744-6570.2011.01190.x.

Spector, P. E. (1994). Job Satisfaction Survey. Department of Psychology, University of South Florida.

Stasser, G., \& Titus, W. (1985). Pooling of unshared information in group decision making: Biased information sampling during discussion. Journal of Personality and Social Psychology, 48(6), 1467-1478. doi:10.1037/0022-3514.48.6.1467

Stasser, G., \& Titus, W. (1987). Effects of information load and percentage of shared information on the dissemination of unshared information during group discussion. Journal of Personality and Social Psychology, 53(1), 81-93. doi:10.1037/0022-

972 3514.53 .1 .81 
Page 45 of 50

973 Steele-Johnson, D., Beauregard, R. S., Hoover, P. B., \& Schmidt, A. M. (2000). Goal orientation 974 and task demand effects on motivation, affect, and performance. Journal of Applied 975 Psychology, 85(5): 724-738. doi:10.1037/0021-9010.85.5.724.

976 Tennyson, R. D., \& Jorczak, R. L. (2008). A conceptual framework for the empirical study of 977 games, Computer games and team and individual learning: (pp. 3-20). Mahwah,NJ:

$978 \quad$ Erlbaum.

979 VandeWalle, D. (1997). Development and validation of a work domain goal orientation 980 instrument. Educational and psychological measurement, 57(6): 995-1015.

981 doi:10.1177/0013164497057006009

982 Wittenbaum, G. M., Hollingshead, A. B., \& Botero, I. C. (2004). From Cooperative to Motivated 983 Information Sharing in Groups: Moving Beyond the Hidden Profile Paradigm.

984 Communication Monographs, 71(3), 286-310. doi:10.1080/0363452042000299894

985 Zhang, Z.-X., Hempel, P., Han, Y.-L., \& Tjosvold, D. (2007). Transactive memory system links 986 work team characteristics and performance. Journal of Applied Psychology, 92(6), 1722987 1730. doi:10.1037/0021-9010.92.6.1722 
FIGURE 1: Hypothetical model.

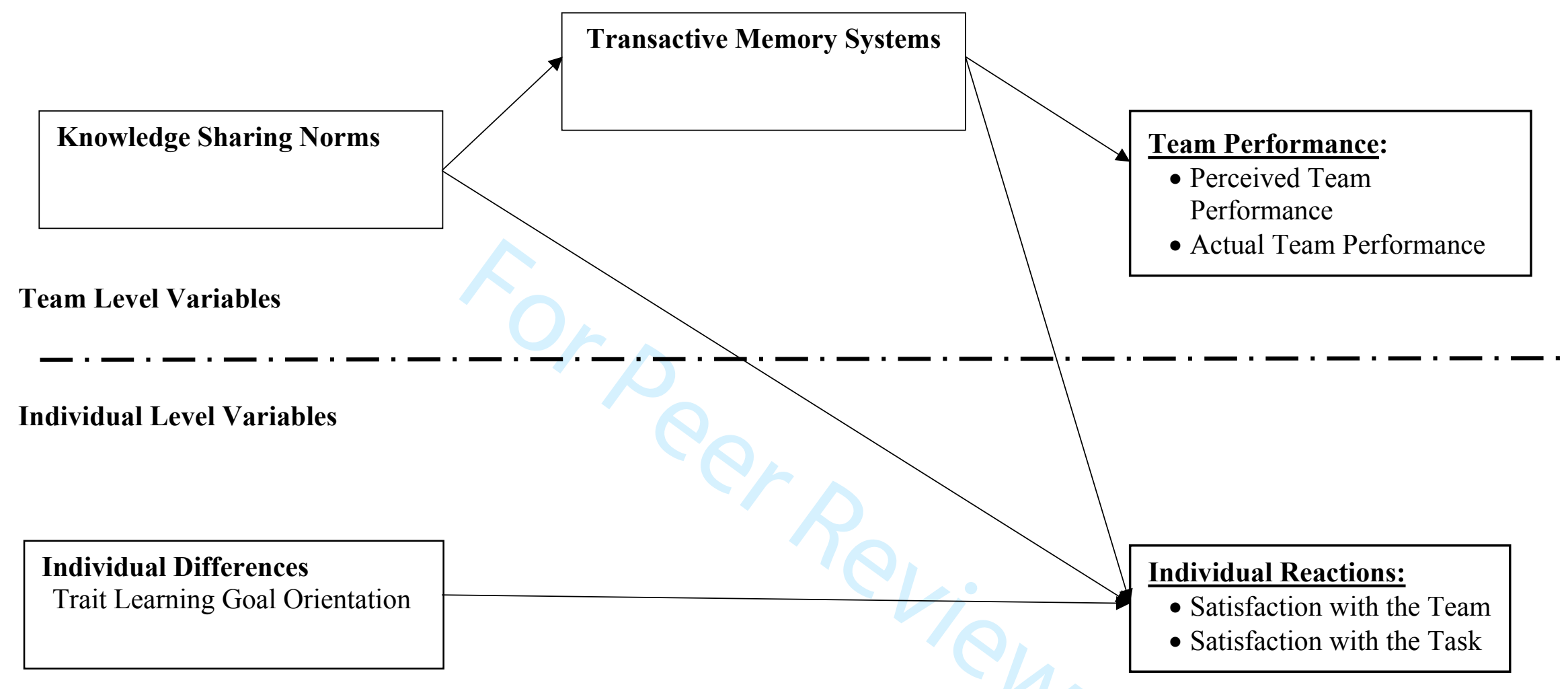

Variables assessed in this study: variables above the dashed line represent team-level constructs, variables below the dashed line represent individual-level constructs. 
TABLE 1: Aggregation results for study predictor variables.

\begin{tabular}{|c|c|c|c|c|c|c|c|c|c|}
\hline \multirow[b]{2}{*}{ Measure } & \multicolumn{2}{|c|}{$r_{W G(J) \text {, uniform }}$} & \multicolumn{7}{|c|}{$r_{W G(J), \text { measure-specific }}$} \\
\hline & Mean & SD & Shape & $\sigma^{2} \mathrm{e}$ & Mean & $\mathrm{SD}$ & $\mathrm{F}$ ratio & $\mathrm{ICC}(1)$ & $\mathrm{ICC}(2)$ \\
\hline Knowledge sharing norms & 0.87 & 0.26 & Slight Skew & 2.90 & 0.81 & 0.29 & $2.02^{* *}$ & 0.30 & 0.50 \\
\hline Transactive memory systems & 0.95 & 0.05 & Normal & 1.04 & 0.69 & 0.37 & $1.95^{*}$ & 0.29 & 0.49 \\
\hline Perceived team performance & 0.78 & 0.32 & Slight Skew & 1.85 & 0.69 & 0.36 & $2.32^{* *}$ & 0.36 & 0.57 \\
\hline
\end{tabular}

Notes. $\mathrm{SD}=$ standard deviation of $\mathrm{r}_{\mathrm{WG}(J)}$ values; shape $=$ the shape of an alternative null distribution; $\sigma^{2} \mathrm{e}=$ variance of the alternative null distribution. Excel tool from Biermann, Cole, \& Voelpel (2012).

${ }^{* *} \mathrm{p}<.01$

${ }^{*} \mathrm{p}<.05$ 
Table 2. Descriptive Statistics

2-1: Among Level-1 (Individual) variables

\begin{tabular}{lccccc}
\hline & Mean & Std. Dev & 1 & 2 & 3 \\
\hline 1. Trait learning goal orientation & 4.66 & 0.79 & $(.78)$ & & \\
2. Satisfaction with the team & 6.08 & 0.80 & .05 & $(.72)$ & \\
3. Satisfaction with the task & 4.57 & 1.37 & $.30^{* *}$ & $.30^{* *}$ & $(.91)$ \\
\hline
\end{tabular}

2-2: Among Level-2 (Team) variables

\begin{tabular}{lcccccc}
\hline & Mean & Std. Dev & 1 & 2 & 3 & 4 \\
\hline 1. Knowledge sharing norms & 5.44 & 0.94 & $(.96)$ & & & \\
2. Transactive memory systems & 3.62 & 0.42 & $.55^{* *}$ & $(.85)$ & & \\
3. Perceived team performance & 4.47 & 0.94 & $.57^{* *}$ & $.75^{* *}$ & $(.95)$ & \\
4. Actual team performance $^{\text {a }}$ & 6.22 & 9.24 & .05 & .21 & $.32^{*}$ & - \\
\hline
\end{tabular}

Team Level $n=42$; Individual Level $n=100$; Cronbach alpha reliabilities are listed on the diagonal. $* * \mathrm{p}<0.01$ level; * $\mathrm{p}<0.05$ level; $\tau \mathrm{p}<0.10$ level. (All 2-tailed tests).

${ }^{a}$ Natural Logarithm of Cumulative Net Income 
Table 3. Estimates from random coefficient models predicting level-one satisfaction outcomes.

\begin{tabular}{|c|c|c|c|c|c|c|}
\hline & \multicolumn{2}{|c|}{ Model 1} & \multicolumn{2}{|c|}{ Model 2} & \multicolumn{2}{|c|}{ Model 3} \\
\hline & Satisfaction & Satisfaction & Satisfaction & Satisfaction & Satisfaction & Satisfaction \\
\hline & With Team & With Task & With Team & With Task & With Team & With Task \\
\hline \multicolumn{7}{|l|}{$\underline{\text { Fixed Effects }}$} \\
\hline Intercept & $6.18^{* *}$ & $4.56^{* *}$ & $6.18^{* *}$ & $4.56^{* *}$ & $6.18^{* *}$ & $4.55^{* *}$ \\
\hline & $(0.09)$ & $(0.17)$ & (0.09) & $(0.15)$ & $(0.06)$ & $(.12)$ \\
\hline \multirow[t]{3}{*}{ Lvl 1 - Trait learning goal orientation } & & & 0.16 & $0.76^{* *}$ & 0.01 & $0.49^{*}$ \\
\hline & & & 0.16 & $0.44 * *$ & 0.01 & $0.28 *$ \\
\hline & & & $(0.17)$ & $(0.28)$ & $(0.12)$ & $(0.23)$ \\
\hline \multirow[t]{3}{*}{ Lvl 2 - Knowledge sharing norms } & & & & & $0.33^{* *}$ & 0.09 \\
\hline & & & & & $0.39 * *$ & 0.06 \\
\hline & & & & & $(0.08)$ & $(0.15)$ \\
\hline \multirow[t]{3}{*}{ Lvl 2 - Transactive memory systems } & & & & & $0.57^{* *}$ & $1.43^{* *}$ \\
\hline & & & & & $0.30^{* *}$ & $0.44^{* *}$ \\
\hline & & & & & $(0.19)$ & $(0.36)$ \\
\hline \multicolumn{7}{|l|}{$\underline{\text { Random Effects }}$} \\
\hline Level-1 & $0.41^{* *}$ & $1.25^{* *}$ & $0.41^{* *}$ & $1.23^{* *}$ & $0.40^{* *}$ & $1.26^{* *}$ \\
\hline & $(0.08)$ & $(0.23)$ & $(0.08)$ & $(0.23)$ & $(0.06)$ & $(0.23)$ \\
\hline \multirow[t]{2}{*}{ Intercept (Team) } & $0.21^{*}$ & $0.61^{*}$ & $0.20^{*}$ & $0.43^{*}$ & 0.00 & 0.05 \\
\hline & $(0.09)$ & $(0.26)$ & $(0.09)$ & $(0.23)$ & - & $(0.16)$ \\
\hline \multicolumn{7}{|l|}{$\underline{\text { Model Fit }}$} \\
\hline Deviance (-2 Log Likelihood) & 228.2 & 338.2 & 227.3 & 331.2 & 192.2 & 310.6 \\
\hline Decrease in Deviance & - & - & 0.90 & $7.00^{* *}$ & $35.1^{* *}$ & $20.6^{* *}$ \\
\hline $\mathrm{ICC}^{\mathrm{a}}$ & 0.34 & 0.33 & 0.33 & 0.26 & 0.00 & 0.04 \\
\hline$\Delta R^{2}$ between-team $^{\mathrm{b}}$ & - & - & 0.04 & 0.30 & 1.00 & 0.88 \\
\hline$\Delta R_{\text {within-team }}{ }^{\mathrm{c}}$ & - & - & 0.00 & 0.00 & 0.03 & 0.00 \\
\hline
\end{tabular}

Model 3 Indirect Effects: Knowledge Sharing Norms $\rightarrow$ TMSs $\rightarrow$ Satisfaction With Team $[(\beta=0.07, p<0.05$, $(C I$ 95\%: 0.019, 0.129)] Knowledge Sharing Norms $\rightarrow$ TMSs $\rightarrow$ Satisfaction With Task $[(\beta=0.07$, n.s., $(C I$ 95\%: -0.005, 0.149)]

Note: ${ }^{*} \mathrm{p}<.05 ;{ }^{* *} \mathrm{p}<.01$. Values based on SAS PROC MIXED with grand mean centered predictors. Entries show unstandardized parameter estimates with standard errors in parentheses. Standardized predictor coefficients are in italics. Estimation method $=$ ML. Degrees of freedom method is between-within. ${ }^{\text {a }}$ ICC $=\left[\tau^{00} /\left(\tau^{00}+\sigma_{e}^{2}\right)\right] .{ }^{\mathrm{b}} \mathrm{R}_{2}^{2}\left[\left(\tau^{00}-\tau^{00} \mid \mathrm{m}\right) / \tau^{00}\right]$ represents the percentage reduction of level two variance. ${ }^{\mathrm{c}} \mathrm{R}_{1}^{2}\left[\left(\sigma_{e}^{2}-\sigma_{e}^{2} \mid \mathrm{m}\right) / \sigma_{e}^{2}\right]$ represents the percentage reduction of level one variance. Indirect effects for the 2-2-1 model were assessed using MPLUS version 8.3. Transactive memory systems are denoted as TMSs. 
Table 4: Multiple regression results for aggregated team level variables.

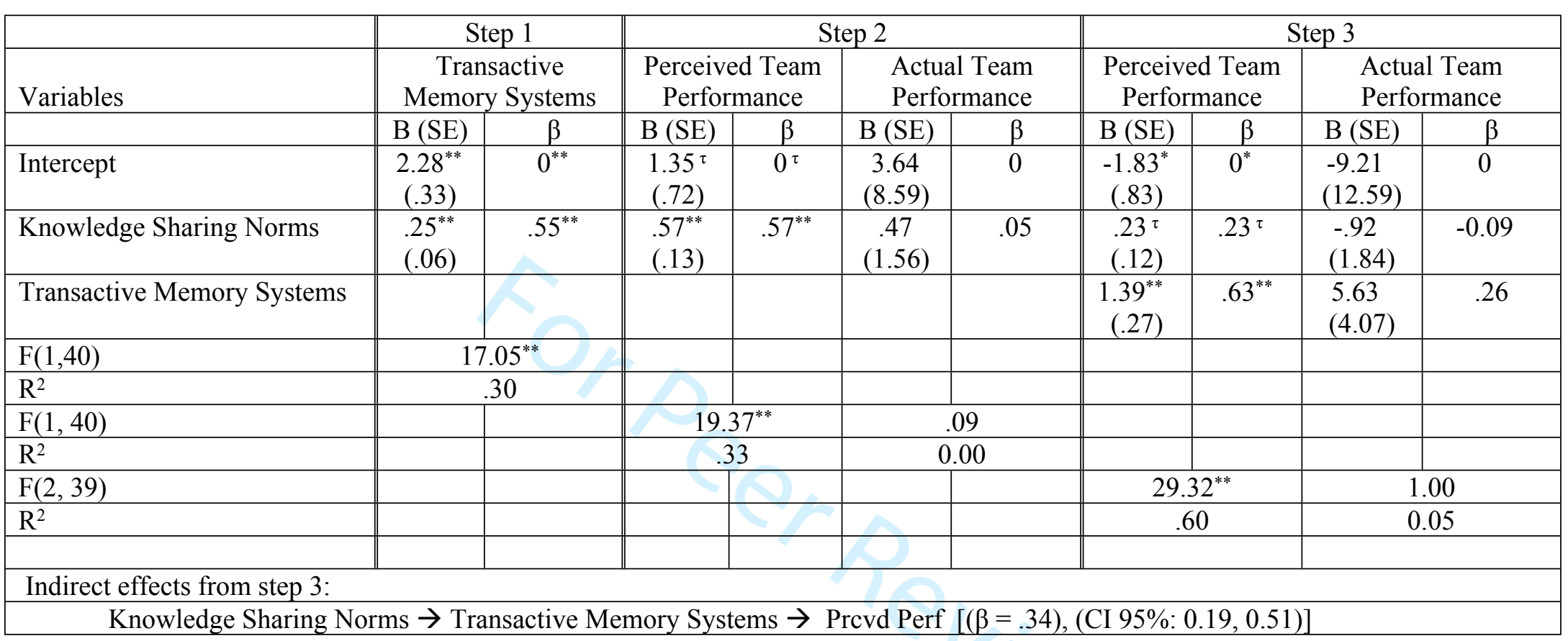

$\mathrm{N}=42$ teams. $\mathrm{B}=$ unstandardized beta; $\beta=$ standardized beta; $\mathrm{SE}=$ Standard Error. Values based on SAS PROC REG. Indirect effects calculated using PROCESS version 3.3.

$\tau<.10 ;{ }^{*} \mathrm{p}<.05 ;{ }^{* *} \mathrm{p}<.01$ 